\title{
Efficient Process Development for Cellulosic Ethanol Fermentation from Cassava Pulp
}

\author{
Weeraya Samnuknit, Pailin Boontawan, and Apichat Boontawan
}

\begin{abstract}
Ethanol has gain an increasing popularity to be used as biofuels. Various renewable agricultural feed stocks can be used for the fermentation process especially lignocellulosic materials. Pre-treatment of these materials for lignin removal is essential in order to obtain cellulose and hemi-cellulose. In this work, saccharification of cellulosic cassava pulp employed 2 steps of alkaline pretreatment, and enzymatic conversion. Experimental results showed that the reducing sugar was obtained at about $714 \mathrm{mg} / \mathrm{g}_{\text {substrate }} . S$. cerevisiae, and $P$. stipitis showed its ability to ferment glucose and xylose, an abundant $C_{5}$ monosaccharide in lignocellulose materials. The produced fermentable sugars can be further converted to ethanol to 40.50 $\mathrm{g} / \mathrm{L}$. The process development of this particular system still required further pilot scale tests as well as process simulation. These results could pave a way for the application in an industrial scale cellulosic ethanol production.
\end{abstract}

Index Terms-Cellulosic ethanol, cassava pulp, saccharification, fermentation.

\section{INTRODUCTION}

Nowadays, the issue of power management is something that must be implemented urgently. Therefore, the study of renewable energy in various forms of biofuels is very important. Many agricultural products can be applied as a raw material in the production of bio-fuels, for example, bio-diesel, and bio-ethanol, etc. In particular, the production of bio-ethanol has gained worldwide attention because it could be a fuel for gasoline engines directly. Lignocellulose is one of the world's most abundant renewable resources such as rice straw, sugarcane bagasse, corn cob, etc. [1]. Most of lignocellulosic material comprises of cellulose, hemicellulose, and lignin [2]. The first step that needs to be carried out is lignin removal by using different process conditions to obtain pure cellulose and hemicellulose. After that, the fraction was converted to reducing sugars by using acid hydrolysis process or by enzymatic pre-treatment as the substrate in the fermentation process by ethanol-fermenting microorganisms such as S. cerevisiae, E. coli, Z. mobilis or P. stipitis, etc. An ethanol production of $36.7 \mathrm{~g} / \mathrm{L}$ from pretreated rice straw was observed from $8 \%$ of glucose within $36 \mathrm{~h}$ with a conversion efficiency of $90.1 \%$ [3]. Wheat straw hydrolysates provided the highest sugar concentrations, $31.82 \mathrm{~g} / \mathrm{L}$ glucose, and $13.75 \mathrm{~g} / \mathrm{L}$ xylose, the fermentation yielded promising results

Manuscript received January 3, 2017; revised May 5, 2017. This work was financially supported by the Energy Policy and Planning Office, The Ministry of Energy, Thailand under contract no. 01/2559.

The authors are with the School of Biotechnology, Institute of Agricultural Technology, Suranaree University of Technology, Nakhon Ratchasima, Thailand 30000 (e-mail: weeraya.samnuknit@ksb.com, panvichit@yahoo.com, apichat@sut.ac.th) including ethanol concentration of $17.37 \mathrm{~g} / \mathrm{L}$ [4]. Thailand is a world leader in cassava starch manufacturer. During starch extraction process, a large amount of cassava pulp was produced as a by-product. It is considered as a cheap, and readily available raw material for cellulosic ethanol production [5]. From these reasons, the cassava pulp was chosen in the production of cellulosic ethanol in this research work.

In order to use lignocellulosic resources for biotechnological purposes, a desirable strain is expected to utilize various fermentable sugars. Saccharocymces cerevisiae and Pichia stipitis are yeast strains that can ferment ethanol from glucose and xylose which are the main sugars obtained by the hydrolysis of cellulose and hemicellulose fraction of cassava pulp. The aims of the present study include removal of the residual starch in order to obtain only cellulosic material, pre-treatments using acid and alkaline solutions, enzymatic saccharification, and fermentation, respectively.

\section{PROCEDURE}

\section{A. Microorganism}

S. cerevisiae and P. Stipitis were purchased from the Thailand Institute of Science and Technological Research (TISTR). Each strain was streaked the colony on the nutrient agar type of Yeast Peptone Dextrose agar (2\% w/v dextrose, $1 \% \mathrm{w} / \mathrm{v}$ yeast extract, $2 \% \mathrm{w} / \mathrm{v}$ tryptone, and $1.5 \% \mathrm{w} / \mathrm{v}$ agar). The agar plate was kept in a refrigerator at $4{ }^{\circ} \mathrm{C}$, and sub-culture of the strain was carried out for every fortnight.

\section{B. Preparation of Cellulosic Cassava Pulp}

Since the fresh cassava pulp obtained from a tapioca manufacturing plant still contains some starch (Fig. 1A), it underwent the process of residual starch removal in order to obtain only cellulosic cassava pulp. The fresh pulp was mixed with distilled water at the weight ratio of $1: 1$ before gelatinization by increasing the temperature to $70{ }^{\circ} \mathrm{C}$ as shown in Fig. 1B. The mixture was mixed with a thermostable $\alpha$-amylase (Termamyl $^{\circledR}, \quad$ Novozymes, Denmark), and increased the temperature to $90{ }^{\circ} \mathrm{C}$ for $1 \mathrm{~h}$. Subsequently, a gluco-amylase (Spirizyme Fuel ${ }^{\circledR}$, Novozymes, Denmark) was added, and the temperature of the solution was decreased to $70{ }^{\circ} \mathrm{C}$ for $2 \mathrm{~h}$ [6]. The slurry was then pressed through a filter bag in order to separate liquid from solid. The solid was continuously washed with tap water through a 100 mesh screen until a colorless solution was obtained. The cellulosic cassava pulp (Fig. 1C) was obtained after drying at $75^{\circ} \mathrm{C}$ until constant weight. Finally, the cellulosic cassava pulp was 
sieved through a $2 \mathrm{~mm}$ mesh, and was stored in a dry place until use.

(A)

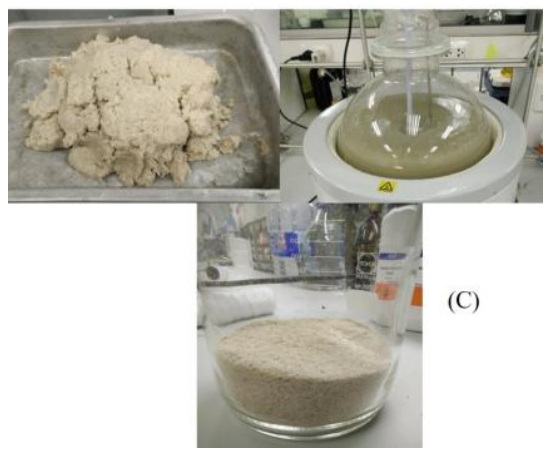

Fig. 1. Starch hydrolysis during cellulosic cassava pulp preparation.

\section{Pre-treatment of Cellulosic Cassava Pulp}

Preliminary analysis of the chemical composition of cellulosic cassava pulp revealed that it comprised of cellulose, hemicellulose, lignin, protein and ash content, respectively. Acid and alkaline pre-treatment were investigated as the pre-treatment step. Cellulosic cassava pulp prepared in the previous section was treated with $\mathrm{H}_{2} \mathrm{SO}_{4}$ and sodium hydroxide $(\mathrm{NaOH})$ at various concentrations ranging from 0 to $4 \mathrm{wt} \%$, and put in sealed bottles. Temperatures were adjusted at the range of $60-120{ }^{\circ} \mathrm{C}$ with the incubation time of 10-30 min, respectively [7]. The solid loading was at $10 \%$ wt. The liquid was separated from insoluble solid by simple filtration before being washed the solids with hot water $90{ }^{\circ} \mathrm{C}$ until $\mathrm{pH}$ neutral. The samples were dried at $105^{\circ} \mathrm{C}$ overnight for measurement of weight loss, and were subjected to further saccharification analysis [8].

\section{Saccharification}

Cellulase enzyme (Viscozyme ${ }^{\circledR}$, Denmark) was employed for the saccharification process with the used enzyme dosages between 5-20 FPU/g [9]. The cellulosic cassava pulp obtained from the previous section was mixed by distilled water until volume reached $100 \mathrm{~mL}$ before an addition of the enzyme. Enzymatic treatment was carried out at suitable condition for 24 hours, shaking $100 \mathrm{rpm}$ to complete digestion [10]. During the digestion process, samples were taken for determination of the reducing sugar. The sample was centrifuged at a speed of $8000 \mathrm{rpm}$ for $15 \mathrm{~min}$. The supernatant was analyzed for reducing sugar by using HPLC.

\section{E. Inoculum Cultivation}

Seed cultivation was separately prepared by growing a single colony of each strain from YPD agar into a $50 \mathrm{~mL}$ shake flask, and was incubated at $35^{\circ} \mathrm{C}$, rotational speed of $200 \mathrm{rpm}$ for $24 \mathrm{~h}$. The regenerated culture from agar slant was transferred to the shake flask. The composition of the pre-culture (a modified YPD) medium was as follows; $90 \mathrm{~g} / \mathrm{L}$ of reducing sugars obtained from the previous section, $10 \mathrm{~g} / \mathrm{L}$ of yeast extract, $20 \mathrm{~g} / \mathrm{L}$ of peptone, $20 \mathrm{~g} / \mathrm{L}$ of glucose, respectively [11]. The $\mathrm{pH}$ of the medium was adjusted to 6.5 by $3 \mathrm{M} \mathrm{NaOH}$ prior to sterilization.

\section{F. Ethanol Fermentation in Batch Fermentation Process}

The cellulosic cassava pulp hydrolysate was used as the substrate for ethanol fermentation. Batch fermentation was carried out in a 5-L bioreactor (BIOSTAT ${ }^{8}$ B plus, Sartorius, Germany). The medium was prepared at $4.0 \mathrm{~L}$, and autoclaved at $121^{\circ} \mathrm{C}$ for 15 minutes. After sterilization, the fermentation medium was inoculated with $5 \%(\mathrm{v} / \mathrm{v})$ of each seed culture (total $10 \% \mathrm{v} / \mathrm{v}$ ). An external electric control unit was used to monitor and regulate the condition of the fermentation broth. Temperature was set at $30^{\circ} \mathrm{C}$, and the agitation speed was maintained at $250 \mathrm{rpm}$. The $\mathrm{pH}$ was measured by a $\mathrm{pH}$ combined electrode (Mettler Toledo, Switzerland), and was automatically maintained at a set point (5.5) by an addition of acid solution (2.0 $\mathrm{M}$ of $\left.\mathrm{H}_{2} \mathrm{SO}_{4}\right)$, or base solution (2.0 $\mathrm{M}$ of $\mathrm{NaOH})$. Fermentation process was monitored for cell concentration, ethanol concentration, and reducing sugar concentration, respectively.

\section{G. Analysis}

During fermentation, $10 \mathrm{~mL}$ of the medium was taken for analysis. Samples were centrifuged at 8,000 rpm for $2 \mathrm{~min}$ in order to separate the yeast cell. The liquid (supernatant) was removed and the precipitate was re-suspended with the same volume using phosphate buffer prior to dilute to a suitable concentration. The supernatant was filtered through a $0.2 \mu \mathrm{m}$ filter before further analysis. Determination of cell concentration was carried out using a spectrophotometer at $600 \mathrm{~nm}$ wavelength. Ethanol concentration (g/L) was analyzed by gas chromatography (SRI Instrument, USA) with capillary column, and a flame ionization detector (FID). The GC column was a $30 \mathrm{~m} \times 0.32 \mathrm{~mm}$ fused silica capillary column (Carbowax®, Restek, USA) [12]. The injector and detector were set at 200 , and $250{ }^{\circ} \mathrm{C}$, respectively. The oven was operated at programmed temperature from 40 to $120{ }^{\circ} \mathrm{C}$ with the rate of $10{ }^{\circ} \mathrm{C} / \mathrm{min}$ using helium gas as a carrier gas and $\mathrm{H}_{2}$ as a flaming gas. The ethanol yield $(\mathrm{Yp} / \mathrm{s}, \mathrm{g} / \mathrm{g})$ and volumetric ethanol productivity $(\mathrm{g} / \mathrm{L} / \mathrm{h})$ were then calculated. The reducing sugar was analyzed by HPLC (Merck-Hitachi) equipped with an Aminex HPX-87 H column (300 mm $\times 7.8$ $\mathrm{mm}$, Bio-Rad Co., USA) and RI detector. The column temperature was maintained at $40{ }^{\circ} \mathrm{C}$. The mobile phase was 1 $\mathrm{mM} \mathrm{H}_{2} \mathrm{SO}_{4}$ at flow rate of $0.6 \mathrm{~mL} / \mathrm{min}$. Then, $5 \mu \mathrm{L}$ of the sample was injected into the HPLC system. Brunauer-Emmett-Teller (BET) surface area analysis before and after pre-treatment was carried out using nitrogen adsorption method [13]. Briefly, the dried sample (0.5 g) was put into a sample tube and outgassed in order to remove the humidity and volatile compounds from the surface of the sample. Vacuum condition was applied at $25 \mathrm{mBar}, 75^{\circ} \mathrm{C}$, and the duration time of $4 \mathrm{~h}$ prior to analysis. The $\mathrm{N}_{2}$ was purged to adsorb on the cassava pulp surface until the equilibrium condition was established. The BET surface area and pore volume was then calculated from the $\mathrm{N}_{2}$ adsorption/desorption curve.

\section{RESULTS AND DISCUSSION}

\section{A. Chemical Composition and Pre-treatment of Cellulosic Cassava Pulp}

The intrinsic characteristic of native lignocellulosic materials make it resistant to biodegradable by enzymatic method. As a result, pre-treatment of lignocellulosic materials 
is therefore the first step for bioethanol production, and is also the most challenging step affecting the digestibility of cellulose and hemi-cellulose to produce fermentable sugars. After starch removal, Fig. 2 shows a chemical composition analysis of dried cellulosic cassava pulp which contained $32.57 \%$ of cellulose, $4.35 \%$ of lignin, $11.64 \%$ of hemicellulose, and $2.88 \%$ ash, respectively. In addition, the value of Nitrogen-Free Extract (NFE), Neutral Detergent Fiber (NDF), and Acid Detergent Fiber (ADF) were reported at $57.63 \%, 52.19 \%$, and $40.75 \%$, respectively. The composition analysis of cellulosic cassava pulp revealed that it contained a substantial amount of cellulose and hemicellulose which represented a valuable source of fermentable sugars for bio-ethanol fermentation.

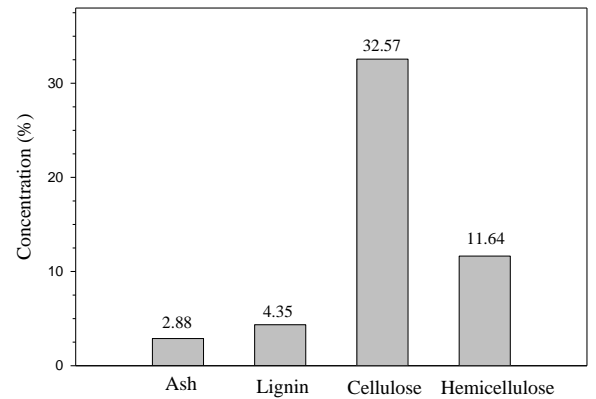

Fig. 2. The chemical composition of cellulosic cassava pulp.

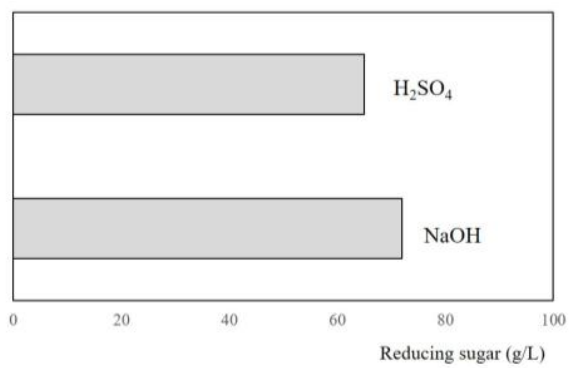

Fig. 3. Effect of acid and alkaline pre-treatments on the yield of reducing sugar after saccharification with cellulase enzyme.

Because lignin is formed as a lignin shield that limits the accessibility of cellulose to cellulase enzyme, some of the most promising pre-treatment methods require the application of chemicals such as acids, alkali, salts, oxidants, and solvents, etc. However, only $\mathrm{H}_{2} \mathrm{SO}_{4}$ and $\mathrm{NaOH}$ were investigated in this study at $1 \mathrm{wt} \%$ and $90{ }^{\circ} \mathrm{C}$ for $15 \mathrm{~min}$. Fig. 3 showed that alkali-based method yielded a $17 \%$ higher reducing sugar concentration in comparison to acid pre-treatment after saccharification process. In addition, it has some other advantages such as the requirement of simpler reactor, and the ease of operation. In contrast, $\mathrm{H}_{2} \mathrm{SO}_{4}$ is difficult to recover, and more expensive compared to $\mathrm{NaOH}$. In addition, a major demerit of acid pre-treatment process is its requirement of special corrosion-resistant reactors which are usually expensive both in investment and operation compared to alkaline methods [14]. Therefore, alkaline pre-treatment was considered as an effective method, and was chosen for further experiments. In addition, another compound known to cause inhibition of ethanol fermentation by the yeast is lignin [15]. Because the pulp contained less than $5.0 \%$ of lignin as shown in Fig. 2, this low concentration of inhibitor was negligible to make the problem in the fermentation process for the subsequent step.
Scanning electron microscopy of native cellulosic cassava pulp exhibited irregular morphology due to the presence of thick lignin layer on top of the surface (Fig. 4A). This intact structure of lignin layer made it very difficult to the cellulose enzyme to access to the internal surface area. It was noted that no starch granule was observed in the picture as most of the starch was completely hydrolyzed at the first step. After pre-treatment with alkaline solution, the surface of the cassava pulp became rough and disintegrated, and it showed ordered and rigid fibril structure due to an exposure of the crystalline cellulose as a result of lignin removal as shown in Fig. 4B. The removal of lignin as well as partial swelling of the cellulose fiber resulted in an increase in internal porosity which allowed the cellulose enzyme to access the internal surface areas. In addition, the alkaline pre-treatment affected the external surface of the cassava pulp as confirmed by the BET study. The specific surface area and pore volume of native cassava pulp were reported at $530 \mathrm{~cm}^{2} / \mathrm{g}$ and 0.0015 $\mathrm{cm}^{3} / \mathrm{g}$ whilst the value for alkaline pre-treated cassava pulp were reported at $8,154 \mathrm{~cm}^{2} / \mathrm{g}$ and $0.0025 \mathrm{~cm}^{3} / \mathrm{g}$, respectively. The alkaline pre-treatment resulted in 15.4 fold increase in the specific surface area as well as in pore volume by 1.67 fold, respectively. The evidence of delignification as a result of alkaline pre-treatment was given in Fig. 5. The dark color of the solution suggested that lignin was removed from the pulp. However, process parameters affect the efficacy of the lignin removal rate.

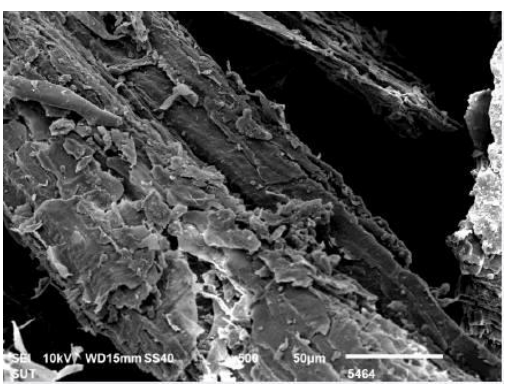

(A)

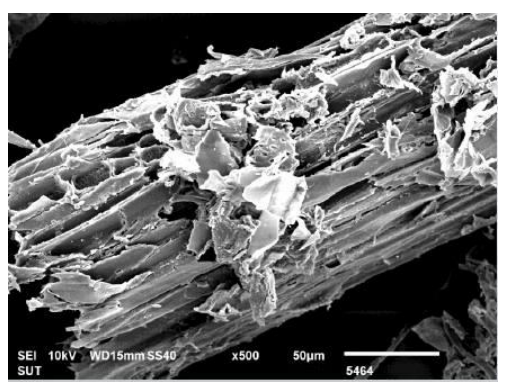

(B)

Fig. 4. Scanning electron microscopes (SEM) picture of native cassava pulp (A), and after treated with $\mathrm{NaOH}(\mathrm{B})(500 \times$ magnification $)$.

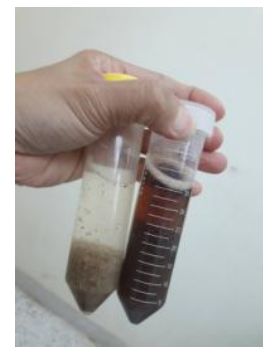

Fig. 5. Experimental result showing the effect of alkaline pre-treatment step for lignin removal (right) in comparison to native cellulosic cassava pulp without alkaline solution (left). 


\section{B. Enzymatic Hydrolysis and Reducing Sugar Yield}

From the pre-treatment step which was evident from the SEM micrographs (Fig. 4B), removal of non-cellulosic materials resulted in a higher percentage of cellulose and more uniform structure which was the main contributors to higher mechanical properties of the cassava pulp. This opened structure facilitates the accessibility of cellulase enzyme in order to yield reducing sugars for ethanol fermentation process.

In this part, optimization for pre-treatment of cellulosic cassava pulp with alkaline solution on reducing sugar yield was investigated. Sodium hydroxide $(\mathrm{NaOH})$ is the most widely used chemical for removed out of the lignin. On the other hands, cellulose and hemicellulose separated out in some portions. Therefore, it is necessary to find the optimum operating condition in order to produce the most efficient lignin removal step. The process conditions that affect the lignin removal and reducing sugar yield include alkaline concentration, temperature, and time, respectively [16]. In this work, the response surface methodology was used for statistical analysis of the experimental data using Design Expert software version 10.0.3. The alkaline concentration, temperature, and time were chosen as independent variables, and the reducing sugar concentration after incubation for $24 \mathrm{~h}$ with cellulase enzyme (10 FPU/g) was the dependent variable. Fig. 6 shows the typical HPLC chromatogram of cassava pulp hydrolysate after alkaline pre-treatment, and incubation with the cellulase enzyme. Only glucose and xylose were taken into account in this work because they were the major reducing sugar products obtained after the saccharification process. Total reducing sugar was also analyzed by using dinitrosalicylic acid (DNS) method.

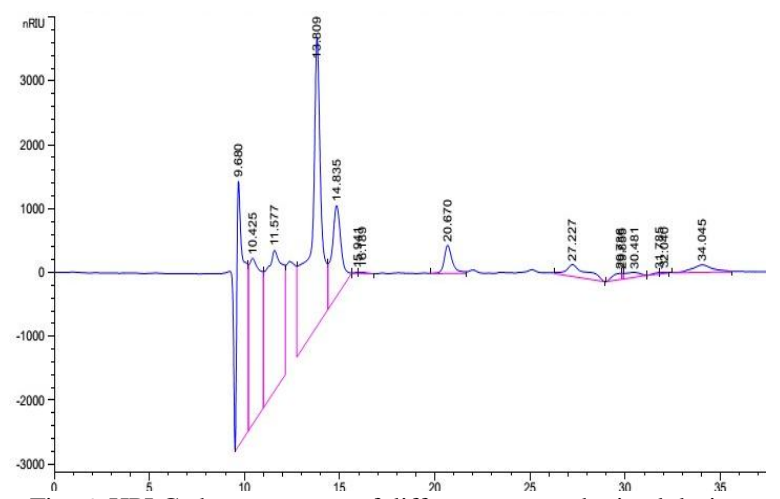

Fig. 6. HPLC chromatogram of different sugars obtained during saccharification of cellulosic cassava pulp. The retention time of glucose and xylose were at 13.809 , and $14.835 \mathrm{~min}$, respectively.

The 3 level 3 factors central composite design (CCD) employed in the pre-treatment step required 15 experiments. The coded levels of the independent variables were shown in Table I. It was noted that the amount of solid (pre-treated pulp) loading was fixed at $10 \%$ wt. The experimental results of reducing sugar concentration obtained after incubation with cellulose enzyme were shown in Table II. The amount of obtained reducing sugars were in the range between $10.52-71.76 \mathrm{~g} / \mathrm{L}$ which corresponded to $714 \mathrm{mg} / \mathrm{g}_{\text {substrate }}$. It is evident from the Table II that the significant factors affecting reducing sugars yield was alkaline concentration, followed by temperature. In contrast, the effect of time possessed the least effect on reducing sugars production. At $0 \%$ wt $\mathrm{NaOH}$ concentration, the lowest reducing sugars concentration was obtained at $10.52 \mathrm{~g} / \mathrm{L}$ indicating that the lignin removal was at minimum. The reducing sugar yield significantly increased when alkaline concentration increased. However, the result of reducing sugars product between 2 and $4 \%$ wt of $\mathrm{NaOH}$ were not significantly different. The temperature also affected the reducing sugars yield. The experimental results revealed that higher temperature resulted in an increasing in reducing sugars. These results can be concluded that high alkaline concentration and high temperature had a significant effect on lignin removal which facilitated enzyme accessibility to the cellulose structure. From the economic point of view, $\mathrm{NaOH}$ concentration at $2 \mathrm{wt} \%, 120^{\circ} \mathrm{C}$, and $10 \mathrm{~min}$ was the optimum condition for pre-treatment of cellulosic cassava pulp.

TABLE I: THE LEVEL AND RANGE OF VARIABLES CHOSEN FOR ALKALINE PRE-TREATMENT EXPERIMENT

\begin{tabular}{lccc}
\hline \hline Independent variables & \multicolumn{3}{c}{ Coded levels } \\
\cline { 2 - 4 } & -1 & 0 & 1 \\
\hline Alkaline concentration (\%wt) & 0 & 2 & 4 \\
Temperature $\left({ }^{\circ} \mathrm{C}\right)$ & 60 & 90 & 120 \\
Time (min) & 10 & 20 & 30 \\
\hline \hline
\end{tabular}

TABLE II: CCD ARRANGEMENT OF CODE LEVEL OF THE INDEPENDENT VARIABLES IN RSM DESIGN

\begin{tabular}{ccccc}
\hline \hline \multicolumn{3}{c}{ Independent variable } & Point types & $\begin{array}{c}\text { Reducing } \\
\text { sugars }(\mathrm{g} / \mathrm{L})\end{array}$ \\
\cline { 1 - 3 } $\mathrm{X}_{1}$ & $\mathrm{X}_{2}$ & $\mathrm{X}_{3}$ & & Factorial point \\
\hline-1 & -1 & -1 & & 10.52 \\
1 & -1 & -1 & Factorial point & 42.22 \\
-1 & 1 & -1 & Factorial point & 14.69 \\
1 & 1 & -1 & Factorial point & 71.76 \\
-1 & -1 & 1 & Factorial point & 22.22 \\
1 & -1 & 1 & Factorial point & 70.22 \\
-1 & 1 & 1 & Factorial point & 28.69 \\
1 & 1 & 1 & Factorial point & 67.77 \\
-1 & 0 & 0 & Axial point & 18.66 \\
1 & 0 & 0 & Axial point & 57.75 \\
0 & -1 & 0 & Axial point & 52.21 \\
0 & 1 & 0 & Axial point & 48.66 \\
0 & 0 & -1 & Axial point & 33.89 \\
0 & 0 & 1 & Axial point & 44.76 \\
0 & 0 & 0 & Center point & 42.21 \\
\hline \hline
\end{tabular}

Factor $\mathrm{X}_{1}, \mathrm{X}_{2}$, and $\mathrm{X}_{3}$ are alkaline concentration, temperature, and time, respectively.

Optimization of pre-treatment step was successfully investigated in the previous section. As a result, the time course production of reducing sugars at different enzyme dosages was studied in this section. The level of enzyme loading was varied from 5 to $20 \mathrm{FPU} / \mathrm{g}$. Fig. 7 showed that an increase of reducing sugar was directly proportional to the enzyme dosages. For all runs, reducing sugars were released steadily during the first $20 \mathrm{~h}$. After this period, the concentration gradually increased until the finishing time of $45 \mathrm{~h}$. The highest reducing sugars content reached up to 80 $\mathrm{g} / \mathrm{L}$ in the case of $20 \mathrm{FPU} / \mathrm{g}$ whereas the values for $5 \mathrm{FPU} / \mathrm{g}$ and $10 \mathrm{FPU} / \mathrm{g}$ were obtained at 41.2 and $72.1 \mathrm{~g} / \mathrm{L}$, respectively. The insignificant increasing in reducing sugars concentration between $10 \mathrm{FPU} / \mathrm{g}$ and $20 \mathrm{FPU} / \mathrm{g}$ suggested that the first enzyme dosage was recommended for the fermentation experiment.

In enzymatic hydrolysis, it was found that the cellulase enzyme worked at the optimum temperature of around $55^{\circ} \mathrm{C}$ (but will be broken down to a temperature of about $80^{\circ} \mathrm{C}$. After pre-treatment step, it was recommended that enzyme 
addition should be carried out when the pre-treated cellulosic cassava pulp was cooled down to the optimum temperature. After this step, reducing sugar released from the cellulosic cassava pulp, it was used as carbon source for the ethanol fermentation by $S$. cerevisiae and $P$. stipitis in the next section.

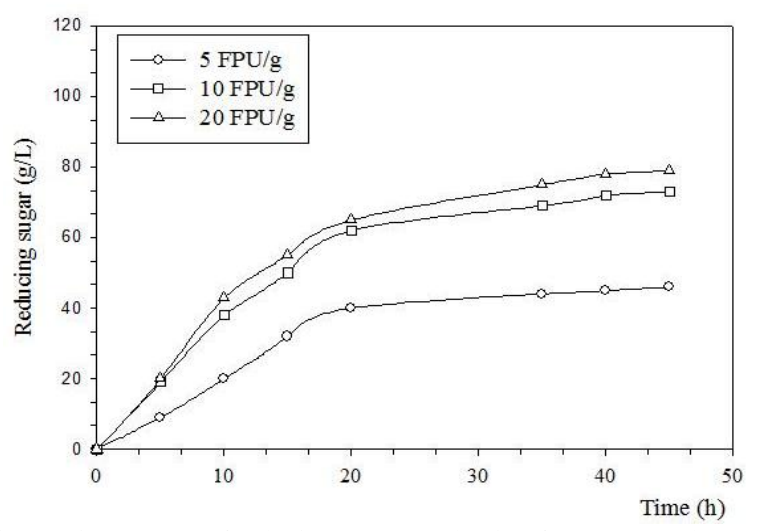

Fig. 7. Time course of reducing sugar production for pre-treated cassava pulp saccharification with cellulose enzyme at different enzyme dosages. Temperature $45^{\circ} \mathrm{C}$, rotational speed $250 \mathrm{rpm}$, and solid loading $10 \% \mathrm{wt}$.

\section{Fermentation Study}

In this part, ethanol fermentations were compared between untreated or native cellulosic cassava pulp and alkaline-treated cellulosic cassava pulp as shown in Fig. 8. It was clearly shown that higher ethanol yield was observed in the case of alkaline pre-treated cassava pulp, while ethanol yield on native cassava pulp was significantly lower. This experimental result again addressed the importance of pretreatment of cellulosic substrate before fermentation. The hydrolysis of cassava pulp produced fermentable sugars which were then utilized by $S$. cerevisiae and $P$. stipitis via pentose phosphate pathway (PPP), then the xylose and glucose have been converted to ethanol.

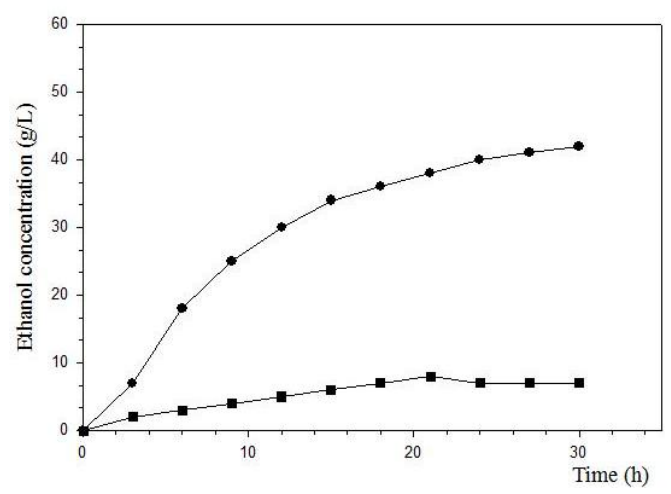

Fig. 8. Time course of ethanol fermentation using native cassava pulp (square symbol), and alkaline-treated cassava pulp (circle symbol).

Fig. 9 illustrates the time course for glucose consumption, ethanol formation, $\mathrm{pH}$ and cell growth, respectively. The concentration of glucose rapidly decreased during the first 15 $\mathrm{h}$ of fermentation time before the consumption rate gradually decreased. However, approximately $8 \mathrm{~g} / \mathrm{L}$ of reducing sugar still remained at the end of fermentation indicating that it was not completely consumed by the yeast cells. The decrease rate of glucose consumption was associated with the increasing ethanol concentration. The ethanol concentration rapidly increased at the first $15 \mathrm{~h}$ with a volumetric productivity of approximately $1.29 \mathrm{~g} / \mathrm{L} / \mathrm{h}$. The maximum ethanol product concentration of $40.5 \mathrm{~g} / \mathrm{L}$ was obtained corresponding to $45.0 \%$ of the theoretical yield. $\mathrm{pH}$ of the fermentation broth slightly decreased from 6.0 to 5.02 at the end of fermentation time. This lowering $\mathrm{pH}$ value probably caused by the formation of carbonic acid during fermentation.

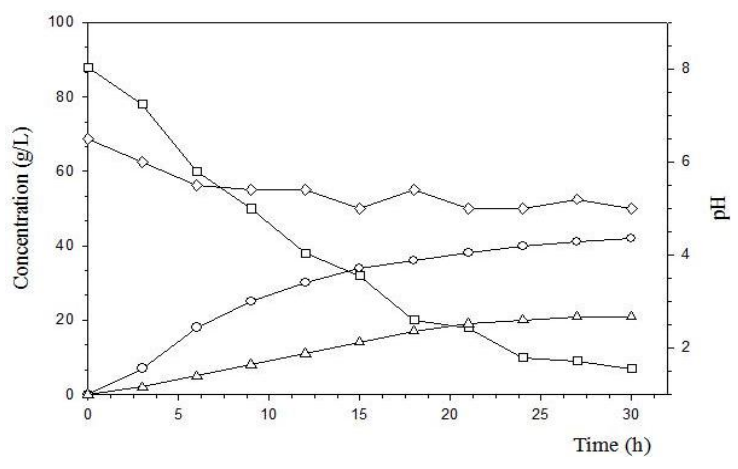

Fig. 9. The relationship between the concentration of reducing sugar ( $\square$ ), Ethanol concentration $(O)$, biomass concentration $(\Delta)$, and $\mathrm{pH}(\diamond)$ in ethanol production during batch fermentation.

Thus, advance in this research was the development of the chemical-based pre-treatment of cellulosic cassava pulp into proprietary ethanol fermentation.

\section{CONCLUSION}

Cellulose materials need to be pre-treated by using alkaline solution, and enzymes for saccharification into fermentable sugars before being used as the carbon source. This carbon source then goes into fermentation by yeast cells to convert the fermentable sugars into ethanol. The optimal conditions for cellulosic cassava pulp by alkaline pre-treatment were $2 \%$ wt $\mathrm{NaOH}, 120{ }^{\circ} \mathrm{C}$, and $10 \mathrm{~min}$ as confirmed by the reducing sugars yield after saccharification process. These results provided insights for utilization of cellulosic cassava pulp for ethanol fermentation using co-culture of $S$. cerevisiae and $P$. stipitis.

\section{REFERENCES}

[1] B. Hahn-Hägerdal, C. F. Wahlbom, M. Gárdonyi, W. H. van Zyl, R. R C. Otero, and L. J. Jönsson, "Metabolic engineering of Saccharomyces cerevisiae for xylose utilization," Adv Biochem Eng Biotechnol, vol. 73, pp. 53-84, 2001.

[2] N. Zhang, H. Sun, J. Li, Y. Wan, Y. Li, and Y. Zhang, "High-titer-ethanol production from cellulosic hydrolysate by an engineered strain of Saccharomyces cerevisiae during an in situ removal process reducing the inhibition of ethanol on xylose metabolism," Process Biochem, vol 51, pp. 967-972, 2016.

[3] A. K. Kumar, B. S. Parikh, E. Shah, L. Z. Liu, and M. A. Cotta, "Cellulosic ethanol production from green solvent-pretreated rice straw," Biocatal Agric Biotechnol, vol. 7, pp. 14-23, 2016.

[4] C. Toquero, and S. Bolado, "Effect of four pretreatments on enzymatic hydrolysis and ethanol fermentation of wheat straw. Influence of inhibitors and washing," Biores Technol, vol. 157, pp. 68-76. 2014.

[5] W. Kaewwongsa, S. Traiyakun, C. Yuangklang, C. Wachirapakorn, and P. Paengkoum, "Protein Enrichment of Cassava Pulp Fermentation by Saccharomyces cerevisiae," J Anim Vet Adv, vol. 10, pp. 2343-2440, 2011.

[6] M. I. Ruiz, C. I. Sanchez, R. G. Torrres, and D. R. Molina, "Enzymatic hydrolysis of cassava starch for production of bioethanol with a colombian wild yeast strain," J. Braz. Chem. Soc., vol. 22, pp. 2337-2343.

[7] J. W. Kim, K. S. Kim, J. S. Lee, S. M. Park, H. Y. Cho, J. C. Park, and J. S. Kim, "Two-stage pretreatment of rice straw using aqueous 
ammonia and dilute acid," Bioresour Technol, vol. 102, pp. 8992-8999, 2011.

[8] C. A. Hubbell and A. J. Ragauskas, "Effect of acid-chlorite delignification on cellulose degree of polymerization," Bioresour. Technol, vol. 101, pp. 7410-7415, 2010.

[9] I. P. Wood, H. G. Cao, L. Tran, N. Cook, P. Ryden, D. R. Wilson, G. K. Moates, S. R. A. Collins, A. Elliston, and K. W. Waldron, "Comparison of saccharification and fermentation of steam exploded rice straw and rice husk," Biotechnol Biofuels, vol. 9, pp. 1-9.

[10] A. Diaz, J. L. Toullec, A. Blandino, I. De Ory, and I. Caro, "Pretreatment of rice hulls with alkaline peroxide to enhance enzyme hydrolysis for ethanol production," Chem Eng Trans, vol. 32, pp. 949-954. 2013

[11] K. M. You, C. L. Rosenfield, and D. C. Knipple, "Ethanol tolerance in the yeast Saccharomyces cerevisiae is dependent on cellular oleic acid content," Appl Environ Microbiol, vol. 69, pp. 1499-1503. 2003.

[12] A. Tangerman, "Highly sensitive gas chromatographic analysis of ethanol in whole blood, serum, urine, and fecal supernatants by the direct injection method," Automation and Analytical Techniques, vol. 43, pp. 1003-1009.

[13] G. L. Guo, W. H. Chen, L. C. Men, and W. S. Hwang, "Characterization of dilute acid pretreatment of silvergrass for ethanol production," Bioresour Technol, vol. 99, no. 1, pp. 6046-6053, 2008.

[14] D. Kumar and G. S. Murthy, "Impact of pretreatment and downstream processing technologies on economics and energy in cellulosic ethanol production," Biotechnol Biofuels, vol. 4, article 27, 2011.

[15] E. C. Bensah and M. Mensah, "Chemical pretreatment methods for the production of cellulosic ethanol: technologies and innovations," Int $J$ Chem Eng, pp. 1-21, 2013.

[16] Q. Ma and V. Rudolph., "Dimensional change behaviour of carribean pine using an environmental scanning electron microscope," Dry Technol. vol. 24, pp. 1397-1403, 2006.

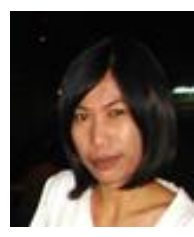

Weeraya Samnuknit was born on October 20, 1985 in Surin province. She obtained her bachelor of engineering degree in chemical engineering from School of Chemical Engineering, Institute of Engineering, Suranaree University of Technology in 2009. Now she Is studying in master's degree of biotechnology.

During study, she received financial support from the Suranaree University of Technology. She worked in the project title of "Extractive fermentation of ethanol using vacuum fractionation technique", in Biofuel Production from Biomass Research Unit, Suranaree University of Technology, Thailand. During this time she had practiced skills in the field of fermentation technology, distillation, and adsorption technique, and she had an experience oral presentation in the title of "A small scale production of motor fuel ethanol using distillation/vapor permeation technique" at the $3^{\text {rd }}$ SUT Graduate Conference, 2010.

Miss Samnuknit has published paper entitled "Extractive Fermentation of Ethanol using Vacuum Fractionation Technique" in the conference proceedings of the ICCBE 2014: International Conference on Chemical and Biological Engineering.

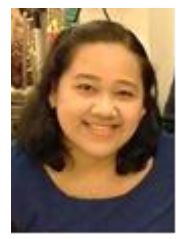

Pailin Boontawan was born on December 29, 1982 in Nakhon Ratchasima, Thailand. She graduated with the bachelor degree of science in biotechnology from Mahasarakham University, Thailand in 2004. She received her Master's Degree in Biotechnology from Suranaree University of Technology in 2006 and doctoral degree of Microbiology in 2012.

She had an experience on visiting research work for one year at the Department of Food Biotechnology, University of Natural Resources and Applied Life Sciences, Vienna, Austria. She had more experience on poster presentation in the title of "Selection of lactic acid bacteria for $\mathrm{L}(+)$ - lactic acid fermentation from cassava starch" of The 3rd International Conference on Renewable Resources and Biorefineries. On oral presentation, she had two experiences in the title of "Utilization of cassava starch supplementing with brewer's yeast extract as nutrient source for possible commercial

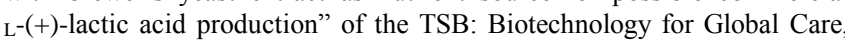
and in the title of "Separation of L (+)-lactic acid from diluted aqueous solutions using continuous electrodeionization (CEDI) technique" of The $2^{\text {nd }}$ SUT Graduate Conference, Nakhon Ratchasima, Thailand.

Dr. Boontawan has published the paper entitled "Extractive fermentation of $\mathrm{L}_{\mathrm{L}}(+)$ - lactic acid by Pediococcus pentosaceus using electrodeionization (EDI) technique", Biochemical Engineering Journal, vol. 54, pp. 192-199, 2011.

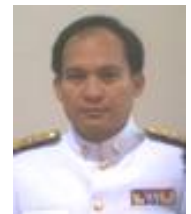

Apichat Boontawan was born on July 1, 1973 in Chaing Mai, Thailand. He graduated with the bachelor's degree in food technology. He got the Royal Thai Government Scholarship and received his master's degree in biochemical engineering from University of Birmingham, UK in 2000 and doctoral degree of chemical engineering from Imperial college London, UK in 2005.

He had an experience on ASEA-UNINET Post-doc research work for one year at Vienna University of Technology, Vienna, Austria (June 2007- May 2008). He work as the lecturer in School of Biotechnology, Institute of Agricultural Technology, Suranaree University of Technology (2005-Present), Thailand. His research is now focusing on bio-separation, fermentation and biochemical engineering.

Assoc. Prof. Dr. Boontawan have published the paper entitled "Extractive fermentation of $\mathrm{L}^{-}(+)-$lactic acid by Pediococcus pentosaceus using electrodeionization (EDI) technique," Biochemical Engineering Journal, vol. 54, pp. 192-199, 2011, the title of Purification of 1-(+)-lactic acid from pre-treated fermentation broth using vapor permeation-assisted esterification in J Mem Sci, vol. 47, pp. 1948-1956, 2014, the title of Nanofiltration coupled with vapor permeation-assisted esterification as an effective purification step for fermentation-derived succinic acid in Process Biochem, vol. 459, pp. 132-142, 2014, and the title of Production of Very-High Purity Succinic Acid from Fermentation Broth using Microfiltration and Nanofiltration-Assisted Crystallization in J Mem Sci, In Press. 2016. 